Title:

\title{
NHS Health Check Programme: A qualitative study of prison experience
}

\section{Authors and Affiliations:}

Marie Williams ${ }^{\mathrm{a}}$, Louise Thomson ${ }^{\mathrm{b}}$, Elizabeth Butcher ${ }^{\mathrm{a}}$, Richard Morriss ${ }^{\mathrm{b}}$, Kamlesh Khuntic $\&$ Chris Packham $^{\mathrm{a}}$

aDuncan MacMillan House, Nottinghamshire Healthcare NHS Trust, Nottingham NG6 3AA.

${ }^{b}$ Institute of Mental Health, University of Nottingham, Nottingham, NG7 2TU.

'Diabetes Research Centre, University of Leicester, Leicester, LE5 4PW.

\section{Corresponding Author:}

Dr Christopher Packham, Medical Directorate, Duncan McMillan House, Nottinghamshire Healthcare NHS Trust, Nottingham NG6 3AA.

Phone: $441159691300 \times 15672$

\section{Chris.packham@nottshc.nhs.uk}

Abstract 195, Main text 3194, Two Tables, Two Figures 


\section{NHS Health Check Programme: A qualitative study of prison experience}

$\underline{\text { Abstract }}$

Background: NHS Health Checks began in England in 2009 and were subsequently introduced into English prisons. Uptake has been patchy and there is limited understanding about factors that may limit or enhance uptake in prison settings. Uptake of this programme is a key policy in reducing the risk of cardiovascular disease and death in these settings.

Method: Semi-structured focus groups were conducted with groups of prisoners (attendees and non-attendees to the health check), prison healthcare staff, custodial staff and ex-prisoners $(n=50)$. Participants were asked about their awareness and experiences of the NHS health check programme in prison.

Results: All groups highlighted barriers for not attending a health check appointment, such as poor accessibility to the healthcare department, stigma and fear. The majority of participants expressed a lack of awareness and discussed common misconceptions regarding the health check programme. Methods of increasing the uptake of health checks through group-based approaches and accessibility to healthcare were suggested.

Conclusions: This study reports on prisoner, staff and ex-prisoner perspectives on the implementation of NHS Health Checks within a restrictive prison environment. These findings have potentially substantial implications for successful delivery of care within offender healthcare services. 


\section{$\underline{\text { Introduction }}$}

Approximately 7 million people in the UK are affected by cardiovascular disease (CVD). ${ }^{1}$ It is a leading cause of natural and premature deaths globally. 2,3 Premature death rates from CVD highlight sizeable health inequalities with mortality rates significantly higher in the most deprived social areas; ${ }^{4}$ prison populations are at particularly high risk. In the UK, one-third of natural cause deaths in prison are due to CVD. ${ }^{5}$ The prevalence of CVD related illnesses is likely to rise due to increasing age of prisoners. ${ }^{6,7}$

A large proportion of prisoners come from poor socio-economic backgrounds with lifestyles that increase health needs. ${ }^{8,9}$ The World Health Organisation deem it to be a human right that prisoners have the same right to healthcare as people in the community. ${ }^{10}$ Subsequently, offender health services should strive to provide such level and quality of support. ${ }^{11}$

The NHS Health Check programme was implemented in England in 2009 and aims to assess the risk of developing CVD in individuals aged 40 to 74 years, every 5 years. ${ }^{2}$ The programme measures healthcare makers, such as Body Mass Index, blood pressure, cholesterol levels and includes lifestyle questions regarding alcohol intake and physical activity. Following testing, patients receive lifestyle advice or subsequent intervention to reduce the risk of developing CVD. The health check was introduced into prisons to provide equitable healthcare. Public Health England (PHE) guidelines for delivering health checks within prison consider the higher risk of CVD in prisoners, so have a lower age criterion starting at 35 years old. ${ }^{12}$

There is currently a dearth of data regarding the uptake of health checks in prison. Within the community an attendance rate, for all those who were invited to a health check, was $30.1 \%$ in 2012 , increasing to $35.5 \%$ in $2019 .{ }^{14}$ For health checks to be effective, they need high levels of take-up from members of the population at risk of CVD. However, those at the highest risk are least likely to attend. ${ }^{15,16} \mathrm{~A}$ prison environment poses different barriers and/or facilitators regarding attendance. ${ }^{17,18}$ It is therefore relevant to investigate the factors which may impact uptake in this environment.

Patient experience is an important factor when considering the overall quality of care. ${ }^{19}$ The use of qualitative methods such as focus groups allows for a comprehensive exploration of experiences and an understanding of the degree of consensus or competing narratives within the 'patient view'. ${ }^{20}$

The prison health check is a new concept with little current insight regarding practice or the perceptions of prisoners. ${ }^{21,22}$ This research formed a part of a larger study exploring CVD risk within prisons. ${ }^{23}$ This qualitative study aims to explore experiences from prisoners, staff and ex-prisoners, 
allowing for an all-encompassing understanding of the implementation of health checks within prison.

\section{Method}

\section{Recruitment and Ethical Procedures}

This research formed part of a large study ${ }^{23}$ and thus recruitment was purposive. The region had 13 male prisons; five were chosen to represent a range of different environments, and healthcare services were approached and agreed to participate in this qualitative research. Prisoners who were eligible to receive a health check ${ }^{12}$ were sent an invitation to take part; either in a focus group for those who had attended a health check, or a focus group for those who had not received and/or who had declined a health check. Eligibility was sought via healthcare clinic lists. Ex-prisoners, from an East Midlands Probation Service, who had served time in prison and who were eligible for a health check, were invited to participate. Healthcare and prison staff were also invited to separate focus groups within each prison. We provided everyone with an Information Sheet outlining the study aims and research governance. At the commencement of each focus group participants had the opportunity to ask further questions and were required to provide written informed consent for their participation.

Ethical approval was obtained from North-East York Research Ethics Committee (16/NE/0133). Approval was granted from NHS England Health Research Authority. Her Majesty's Prison and Probation Service approval was obtained and permission was sought from each prison Governor.

\section{Participants}

Fifty participants took part in 11 focus groups (average 39 minutes); the number of participants in each focus group varied from 2 to 9 (Table 1 ). All prisoners met the health check eligibility criteria ${ }^{12}$. The healthcare staff focus groups involved a variety of different roles including nurses, healthcare assistants and pharmacy technicians Participants were recruited from one community probation service and five prisons; two Category C prisons and three Category B ( 2 local remand and 1 training) prisons. All prisons were closed environments where Category $B$ is a higher risk status than $C .{ }^{24}$

Data collection

Data collection occurred from November 2017 for 13 months. Semi-structured interview schedules were used to guide the focus groups.. The topic guide was broad with open-ended questions to 
allow for in-depth descriptions of experiences. We asked participants to describe what they understood about a health check, their experiences and the barriers and facilitators of having a health check in a prison environment. Researcher MW conducted the focus groups, with cofacilitator EB recording notes. The focus groups were also digitally recorded to ensure quality of data. ${ }^{25}$ It was decided at the point of data saturation data collection would cease.

Analysis

Interviews were transcribed verbatim. We later reviewed the transcripts to ensure accuracy; ${ }^{25}$ participants were not asked to check the transcripts. In order to be theoretically flexible the data were analysed using thematic analysis within a framework approach. ${ }^{26,27}$

The transcripts were analysed and coded by two authors. These codes were used to develop an initial framework and potential themes. Comparisons of the transcripts were made in order to refine the thematic framework and allow for sub-themes to be generated. NVivo 10 was used to manage the data and the analytical processes.

\section{$\underline{\text { Results }}$}

The analysis highlighted a framework of four main topics: understanding and awareness of health checks, attendance, increasing uptake, and providing results. These topics and sub-themes are outlined in Figure 1 and described in detail below. Excerpts from the focus groups are shown in Figure 2.

\section{Understanding and Awareness of Health Checks}

The awareness of the health check programme amongst prisoners and staff varied within individual focus groups but was generally poor. The prison type did not have an impact on the degree of awareness. Some prisoners expressed awareness of health checks from experiences in the community prior to entering prison. Prisoners and staff in all establishments explained there is limited information about health checks and typically only provided within the healthcare department.

The majority of prisoners reported not knowing anything regarding the health check, even if they had previously attended one. Conversely, some prisoners, who had attended a health check, were able to explain what specific tests occur. The majority of all participants had the general misconception that the health check was a general health check-up rather than a specific 
assessment of CVD risk. Only staff who had experience in delivering the health check expressed an accurate understanding.

In addition, many prisoners, from all prisons, reported they expected more from the health check, including tests for other possible diagnoses (such as cancer), or having more invasive tests completed (such as an Electrocardiogram (ECG)). Though these tests do not occur in the health check, this led some prisoners to question the quality of care provided by the prison. One group critiqued some measures and described how some specific questions were not applicable to them due to their current lifestyle and environmental restrictions (such as current smoking and drinking habits).

The majority of prisoners found out about the health check through receiving a written invitation. Some reported the invitation was simply to invite them to a healthcare appointment, not specifying the purpose was for a health check. Almost all groups raised the concern that literacy and language barriers may also limit the understanding of the invitation.

\section{Attendance to Health Check}

\section{Barriers to attending}

All groups reported the biggest barrier to attending a health check appointment was due to the restrictive environment and being unable to physically access the healthcare department. In some prisons prisoners are escorted by staff, whereas others have movement times where prisoners move around areas of the prison independently. Both methods of movement have varying levels of success for accessing healthcare. All groups reported that incidents within the prison disrupt movement. In addition, waiting times within healthcare are also seen as a deterrent; despite having a short appointment, prisoners may be left to wait for long periods in the healthcare department due to movement times. Prisoners reported that the conditions of the waiting-room would deter them from attending; prisoners perceived them to be too crowded and volatile. They reported that the hostile waiting-room could also impact their health check results, particularly blood pressure.

Further issues of accessibility occur if more than one appointment is needed. As per health check guidelines, if a prisoner hadn't given a venous blood sample within 6 months, they would need to attend a second appointment to receive a blood test for cholesterol, kidney function and blood glucose. Health care staff reported this additional appointment causes further inconvenience and a subsequent barrier. 
Many prisoners, largely those who didn't attend their health check appointment, reported that they didn't see of the need to attend an appointment if they felt physically well. This was also echoed by the perception of staff. Apprehension, fear and stigma were frequently cited by all participants as barriers to them attending health checks.

\section{Facilitators to attending}

A key facilitator for prisoners attending their health check appointment stemmed from a motivation to look after themselves in prison. Many individuals are often leading a less chaotic lifestyle in prison than when they were in the community.

The majority of prisoners highlighted that they wanted a health check for reassurance and to prevent health conditions developing. This was particularly highlighted in relation to age, in that with increasing age they wanted to know if everything was ok. Awareness of lifestyle and family history also served as a factor causing a desire for reassurance which facilitated attending an appointment.

\section{Increasing Uptake}

The majority of prisoner groups suggested that health checks could be conducted on a prison wing. Prisoners reported the logistics required for healthcare staff to visit the wings would use fewer resources than the current model of moving and holding large numbers of prisoners across the prison. They also perceived that this method could overcome several barriers relating to the prison regime, staffing, waiting times and communication concerns.

Healthcare staff in one prison reported that prisoners often like to attend appointments with peer support, particularly if they lack understanding or have anxieties regarding their appointment. Other individuals reported that having a specified time within healthcare which solely focused on health checks would be less anxiety provoking; as all appointments at that time would be for health checks, thus limiting the associated stigma of visiting healthcare. Another frequently mentioned method, highlighted in all groups to increase uptake, was to offer an incentive to the prisoners to increase their motivation to attend the health checks.

The majority of groups highlighted other physical healthcare checks and screening programmes within prison. One staff group suggested it would be beneficial to combine such screens together as they measure similar factors to that of the health check.

\section{Providing Health Check Results}


Many prisoners who had received a health check reported they did not receive their results. Some felt that if they hadn't received results, they would deem them to be satisfactory. There was the general consensus that prisoners would only receive results if there were concerns that needed action. This was also echoed from the perspective of healthcare staff; they suggested that the approach of 'no news is good news' is taken as there are not the resources in place to provide feedback to every prisoner. Some groups suggested the waiting time for blood results could explain the lack of feedback regarding the risk score. For those that did receive results there was a lack of understanding regarding the risk score, and no one reported receiving subsequent risk reduction intervention. Staff highlighted that understanding a risk score as a percentage may be a too abstract concept.

Some prisoners reported that waiting for, or not knowing their results caused them to worry. Many suggested that they have a lot of time to ruminate, and a delay in receiving feedback increased anxiety. Conversely, some individuals reported that knowledge of a high CVD risk could also impact the prisoner's mental health, particularly if they are serving a long sentence and feel that there is little need to implement lifestyle changes.

In order to aid understanding, individuals also expressed that in addition to having their results in visual form it would also be beneficial to receive advice leaflets, largely in relation to diet, exercise and specifically about what is possible in the context of the prison environment.

\section{Discussion}

\section{Main findings}

The key finding from this study was the limited awareness and understanding of both the existence and purpose of the health check. There was a common misconception that the health check is a general check-up, rather than a specific assessment of CVD risk, and within this an expectation that a wider variation of tests should be incorporated.

There was a consensus that dominant barriers to attending a health check include a restrictive prison environment impacting accessibility, long waits in a hostile waiting room and poor communication regarding the purpose. Other individual factors also presenting as barriers include negative stigma, anxiety and fear. There was a noticeable difference between attendees and nonattendees with regards to motivation of having a health check, where those who didn't attend reported that an absence of physical illness deterred them. Conversely, many prisoners reported a 
desire for looking after themselves and reassurance were key facilitators to attend a health check appointment.

What is already known?

Nationally, there are varying levels of attendance to health check appointments. ${ }^{13,14}$ Knowledge and awareness is variable within community settings and this hinders uptake. ${ }^{28}$ Similar to the findings of this study, the purpose of the health check has been perceived as a general health screen rather than a cardiovascular screen per se. ${ }^{29} \mathrm{~A}$ lack of knowledge and misconceptions are likely to deter patients from attending.

A number of barriers, specific to the prison environment, have been acknowledged in previous literature, such as limited accessibility to healthcare and lengthy delays. ${ }^{30}$ Previous evidence from the community suggests that providing health checks in easily accessible locations increase uptake. ${ }^{18}$ Research conducted in the community highlighted a disparity regarding communication of results. Similar to this study, some patients received their results, others didn't, and some were informed if their results were 'fine' they wouldn't receive feedback. ${ }^{17,28}$ Woringer et al ${ }^{31}$ indicated that a lack of feedback may lead to false hope and adoption of unhealthy behaviour which could contribute to CVD risk.

What this study adds?

Many of the findings reinforce community literature, largely relating to awareness, knowledge, and misconceptions, though this study also offers a unique perspective of barriers and facilitators within a restrictive prison environment (Table 2 ).

This study reveals the prison environment and accessibility to the healthcare department is not conducive to the current practice of conducting health checks. All groups highlighted that accessing healthcare is a big barrier to attending health check appointments, in particular with regards to limited escorting officers. This has also been echoed by the Chief Inspector of Prisons. ${ }^{32,33}$ Re-locating health checks to a wing-based treatment room may increase uptake, increase awareness and reduce the burden for both prisoners and escorting officers, however this may not be feasible in all establishments. It is advised that efforts to increase uptake to health care appointments should be a joint approach between the prison regime and healthcare department. ${ }^{34}$ In addition to physical 
barriers of the prison environment, individual psychological motivation may also impact uptake to health checks. The Good Lives Mode ${ }^{35}$ assumes humans value primary goods. One primary good is that of 'healthy living and functioning'. All goods are sought after to some degree, but prioritising them is dependent on individuals personal values. This model of offender rehabilitation could explain the differences between those who attended a health check and those who didn't. It also highlights a further reason for a whole prison approach where reaching a goal of positive physical health may lead to achieve other goals in their offender rehabilitation.

As this and previous research indicates, there are numerous physical healthcare checks which cause confusion regarding the purpose of the NHS health check. ${ }^{17}$ Many of the checks are associated with improvements regarding the same risk factors: physical activity, diet, smoking and alcohol intake. ${ }^{36}$ Acknowledging the logistical pressures within a prison environment, it may be beneficial to combine such checks and screens. Suggestions have been made that a CVD risk screen could become part of a mandatory 'opt-out' second reception screen which would ensure all those eligible would receive a health check. ${ }^{8}$ Though in the early phases, such method has been implemented for Blood Borne Virus testing within prison, where testing increased from $4 \%$ to $29 \%$ from 2010 to $2018 .{ }^{37}$

Findings from this study suggest that there could be a high proportion of prisoners not receiving their health check results due to waiting for blood test results. An overall result can only be achieved if the risk calculator contains all of the measurements, and blood tests are often conducted at a separate appointment. 'Point of care testing' could be a way overcome this and allow for completion of the health check in one appointment as well as reducing costs and minimising non-attendance rates. $^{38}$

Another important finding, similar to a community study, ${ }^{17}$ is the majority of prisoners reported that they wanted to receive written feedback. In addition, acknowledging this high-risk population, intervention advice specific to the prison environment should be provided in order to encourage risk reduction behaviour changes..$^{39,40}$

Limitations of the study

Due to the logistics and accessibility of conducting research in a prison, the number of participants in each focus group varied. In some groups the low number of participants could indicate a limited variation of experiences. It is not possible to generalise these findings to female prison populations as this prisoner sample was only male. The focus groups were also conducted solely within a specific region of the UK, and prison establishments in other regions may operate differently. 
Few prisoners who had not had a health check participated. Exploring the experiences of 'nonattendees' therefore may not have been fully captured. Future research, in order to understand this perspective in more detail could involve 1:1 interviews with non-attendees although this may be challenging to conduct in a restrictive environment. Furthermore, CVD risk scores were not recorded for participants. It could be postulated that those with high or low CVD risk may have different experiences. ${ }^{17}$

\section{Conclusion}

A lack of awareness and understanding of health checks, and a restrictive prison environment are not beneficial to the uptake of health checks. This paper suggests several approaches to improve performance, including raising awareness of health checks, improving accessibility to clinics, combining other health screens to reduce burden on staff and prisoners and using point-of-care testing to ensure the entire health check is completed within a single appointment. Only by addressing these issues will healthcare services in prisons improve the implementation of health checks in this high-risk population group. 


\section{Conflicts of interest}

None

\section{Authorship contribution statement}

MW: Acquisition of data, analysis and interpretation of data, drafting the article, review and editing. LT: Conception and design of the study, analysis and interpretation of data, revising the article, review and editing. EB: Acquisition of data, interpretation of data, revising the article, review and editing. RM: Conception and design of the study, revising the article, review and editing. KK: Conception and design of the study, revising the article, review and editing. CP: Conception and design of the study, revising the article, review and editing.

\section{Acknowledgements}

The research was funded by the NIHR CLAHRC East Midlands. We acknowledge the support of the National Institute for Health Research Clinical Research Network (NIHR CRN), Nottinghamshire Healthcare NHS Foundation Trust Research Delivery Team, Lincolnshire Partnership Foundation Trust Research Delivery Team, the Governors and staff at the Offender Healthcare Services involved in the research project. We would also like to thank Derby, Leicestershire, Nottinghamshire and Rutland Community Rehabilitation for participating. RM is also supported by Nottingham NIHR Biomedical Research Centre and NIHR MindTech MedTech and in Vitro Collaboration. We are grateful to Dr Adarsh Kaul, Clinical Director of Offender Health Services at Nottinghamshire Healthcare NHS Foundation Trust, for his role in the early development of this study. 


\section{References}

1. National Institute for Health and Care Excellence. (2018). Impact cardiovascular prevention. Retrieved from https://www.nice.org.uk/media/default/about/what-we-do/intopractice/measuring-uptake/nice-impact-cardiovascular-disease-prevention.pdf

2. Public Health England (2017a). NHS Health Check: Best Practice Guidance. London, Public Health England. Retrieved from: https://www.healthcheck.nhs.uk/seecmsfile/?id=551

3. World Health Organisation. (2017, May 17). Cardiovascular diseases (cardiovascular diseases). Retrieved from: https://www.who.int/news-room/fact-sheets/detail/cardiovascular-diseases-(cvds)

4. Public Health England. (2017b). Public Health Profiles. Retrieved from August 05, 2019 from: https://www.gov.uk/government/publications/health-profile-for-england/chapter-5-inequality-inhealth

5. Public Health England (2014). Health and Justice Health Needs Assessment Template: Adult Prisons. Retrieved from:

https://assets.publishing.service.gov.uk/government/uploads/system/uploads/attachment_data/file /331628/Health_Needs_Assessment_Toolkit_for_Prescribed_Places_of_Detention_Part_2.pdf

6. Bennett, M. (2014). Does every heart matter? Developing a cardiovascular disease service at a high-security prison. British Journal of Cardiac Nursing, 9 (12), 604-606. Doi:

10.12968/bjca.2014.9.12.604

7. Sturge, G. (2018). UK Prison Population Statistics. House of Commons. Retrieved from http://researchbriefings.files.parliament.uk/documents/SN04334/SN04334.pdf

8. Finnie, A, J. (2018). Integrating prevention and health promotion in a London prison. BMJ open quality, 7 (1). Doi: 10.1136/bmjoq-2017-000097

9. House of Commons. (2018). Prison health: Twelfth Report of Session 2017-19. Retrieved from August 05, 2019 from:

https://publications.parliament.uk/pa/cm201719/cmselect/cmhealth/963/963.pdf

10. Moeller, L., Stover, H., Jurgens, R., Gatherer, A., \& Nikogasian, H. (2007). Health in prisons: a WHO guide to the essentials in prison health. Copenhagen, WHO Regional Office for Europe. Retrieved from: https://www.euro.who.int/ data/assets/pdf file/0009/99018/E90174.pdf?ua=1 
11. Royal College of General Practitioners (2018). Equivalence of care in Secure Environments in the UK. London, RCGP. Retrieved from: http://allcatsrgrey.org.uk/wp/download/prisons/RGCP-securegroup-report-july-2018.pdf

12. Public Health England (2017c). Physical Health Checks in Prisons: Programme Guidance. London, Public Health England. Retrieved from: https://www.healthcheck.nhs.uk/seecmsfile/?id=555

13. Robson, J., Dostal, I., Sheikh, A., Eldridge, S., Madurasinghe, V., Griffiths, C., ... \& Hippisley-Cox, J. (2016). The NHS Health Check in England: an evaluation of the first 4 years. BMJ Open, 6. Doi: 10.1136/bmjopen-2015-008840

14. Public Health England. (2019). NHS Health Check. Retrieved August 05, 2019, from: https://fingertips.phe.org.uk/profile/nhs-health-checkdetailed/data\#page/0/gid/1938132726/pat/6/par/E12000004/ati/202/are/E06000015/iid/91112/ag e/219/sex/4

15. Waller, D., Agass, M., Mant, D., Coulter, A., Fuller, A., \& Jones, L. (1990). Health checks in general practice: another example of inverse care? BMJ, 300 (6732), 1115-1118. Doi:

$10.1136 / \mathrm{bmj} .300 .6732 .1115$

16. Willis, A., Rivers, P., Gray, L. J., Davies, M., \& Khunti, K. (2014). The effectiveness of screening for diabetes and cardiovascular disease risk factors in a community pharmacy setting. PLoS One, 9 (4). Doi: 10.1371/journal.pone.0091157

17. Ismail, H., \& Atkin, K. (2015). The NHS Health Check programme: Insights from a qualitative study of patients. Health Expectations, 19 (2), 345-355. Doi: 10.1111/hex.12358

18. Perry, C., Thurston, M., Alford, S., Cushing, J., \& Panter, L. (2016). The NHS health check programme in England: a qualitative study. Health Promotion International, 31 (1), 106-115. Doi: 10.1093/heapro/dau059

19. National Institute of Health and Care Excellence. (2012). Patient experience in adult NHS services: improving the experience of care for people using adult NHS services. Retrieved from: https://www.nice.org.uk/guidance/cg138/resources/patient-experience-in-adult-nhs-servicesimproving-the-experience-of-care-for-people-using-adult-nhs-services-pdf-35109517087429

20. Lehoux, P., Poland, B., \& Daudelin, G. (2006). Focus group research and "the patient's view". Social Science and Medicine, 63 (8), 2091-2104. Doi: 10.1016/j.socscimed.2006.05.016 
21. Abbott, P., Di Giacomo, M., Magin, P., \& Hu, W. A scoping review of qualitative research methods used with people in prison. International Journal of Qualitative Methods, 17 (1), 1-15. Doi: $10.1177 / 1609406918803824$

22. Hek, G. (2006). Unlocking potential: challenges for primary health care researches in the prison setting. Primary Health Care Research and Development, 7 (2), 91-94. Doi: $10.1191 / 1463423606 p c 277$ ed

23. Packham, C., Butcher, E., Williams, M., Miksza, J., Morris, R., \& Khunti, k. (2019). Cardiovascular risk profiles and the uptake of the NHS Healthcheck Programme in male prisoners in six UK prisons. BMJ Open April 2020;0:e033498. Doi:10.1136/bmjopen-2019-033498

24. Prison Reform Trust (n.d.). Categorisation: men's prisons. Retrieved from http://www.prisonreformtrust.org.uk/ForPrisonersFamilies/PrisonerInformationPages/Categorisatio $\mathrm{n} /$ Categorisationmensprisons

25. Newell, R., \& Burnard, P. (2006). Research for evidence-based practice. Oxford: Blackwell 26. Braun, V., \& Clarke, V. (2006). Using thematic analysis in psychology. Qualitative Research in Psychology, 3 (2), 77-101. Doi: 10.1191/1478088706qp063oa

27. Gale, K, N., Heath, G., Cameron, E., Rashid, S., \& Redwood S. (2013). Using the framework method for the analysis of qualitative data in multi-disciplinary health research. BMC medical research methodology, 13 (117). Doi: 10.1186/1471-2288-13-117

28. Harte, E., MacLure, C., Martin, A., Saunders, C. L., Meads, C., Walter, F.,... \& Usher-Smith, A. (2018). Reasons why people do not attend NHS Health Checks: a systematic review and qualitative synthesis. British Journal of General Practice, 68 (666). Doi: 10.3399/bjgp17X693929

29. Baker, C., Loughren, E, A., Crone, D., \& Kallfa, N. (2014). Patients' perceptions of a NHS Health Check in the primary care setting. Quality in Primary Care, 22 (5), 232-237. Retrieved from http://eprints.glos.ac.uk/id/eprint/2104

30. Thomas, E, H., Wang, E, A., Curry, L, A., \& Chen, P, G. (2016). Patients' experiences managing cardiovascular disease and risk factors in prison. Health and Justice, 4 (4). Doi: 10.1186/s40352-0160035-9

31. Woringer, M., Nielsen, J, J., Zibarras, L., Evason, J., Kassianos, A, P., ... \& Soljak, M. (2017). Development of a questionnaire to evaluate patients' awareness of cardiovascular disease risk in 
England's National Health Service Health Check preventive cardiovascular programme. BMJ Open, 7 (9). Doi: 10.1136/bmjopen-2016-014413.

32. HM Inspectorate of Prisons. (2016). HM Chief Inspector of Prisons for England and Wales Annual Report 2015-16. Retrieved from

https://assets.publishing.service.gov.uk/government/uploads/system/uploads/attachment data/file /571732/hmip-annual-report.pdf

33. HM Inspectorate of Prisons. (2019). HM Chief Inspector of Prisons for England and Wales Annual Report 2018-19. Retrieved from

https://assets.publishing.service.gov.uk/government/uploads/system/uploads/attachment data/file /814689/hmip-annual-report-2018-19.pdf

34. Public Health England. (2016). Rapid review of evidence of the impact on health outcomes of NHS commissioned health services for people in secure and detained settings to inform future health interventions and prioritisation in England. Retrieved from

https://assets.publishing.service.gov.uk/government/uploads/system/uploads/attachment data/file \$565231/Rapid review health outcomes secure detained settings .pdf

35. Willis, G. \& Ward, T. (2013). The good lives model: Evidence that it works. In L. Craig, L. Dixon, \& T.A. Gannon (Ed.), What Works in Offender Rehabilitation: An evidence based approach to assessment and Treatment (pp. 305-318). West Sussex, UK: John Wiley \& Sons.

36. Capewell, S., McCartney, M., \& Holland, W. (2015). Invited debate: NHS Health Checks - a naked emperor? Journal of Public Health, 32 (2), 187-192. Doi:10.1093/pubmed/fdv063

37. Public Health England. (2018). Summary Report: National engagement event for bloodborne virus (BBV) opt-out testing in prisons in England, 2017. Retrieved from

https://assets.publishing.service.gov.uk/government/uploads/system/uploads/attachment_data/file /707591/Event_Report_FINAL.pdf

38. El-Osta, A., Woringer, M., Pizzo, E., Verhoef, T., Dickie, C., Ni, M, Z., ... \& Majeed, A. (2017). Does use of point-of-care testing improve cost-effectiveness of the NHS Health Check programme in the primary care setting? A cost-minimisation analysis. BMJ Open, 7 (8). Doi: 10.1136/bmjopen-2016015494 
39. Pulford, A, J., Aspinall, E., Hardie, S., Murphy, L., McDevitt, R, M., \& Watts, M. (2013). Prisoners' self-reported health and attitudes to health promotion initiatives in a Scottish Prison. Health Education Journal, 72 (1), 5-12. Doi: 10.1177/0017896911425536

40. Usher-Smith, J., Harte, E., MacLure, C., Martin, A., Saunders, C., Meads, C., ... \& Mant, J. (2017). Patient experience of NHS health checks: a systematic review and qualitative synthesis. BMJ Open, 7 (8). Doi: 10.1136/bmjopen-2017-017169 
Table Titles

Table 1: Focus Group demographics

$\underline{\text { Table 2: Barries and Potential Solutions }}$

Figure Legend

Figure 1: Themes from the focus groups

Figure 2: Excerpts from focus groups 
Table 1: Focus Group demographics

\begin{tabular}{|l|l|l|l|l|}
\hline $\begin{array}{l}\text { Focus Group } \\
\text { Code }\end{array}$ & $\underline{\mathbf{N}}$ & $\underline{\text { Participant Code }}$ & $\underline{\text { Prison Type }}$ & $\begin{array}{l}\text { Attended or } \\
\text { Declined Health } \\
\text { Check }\end{array}$ \\
\hline FG1 & 3 & PR01-PR03 & $\begin{array}{l}\text { Category B (Local } \\
\text { Remand) }\end{array}$ & Attended \\
\hline FG2 & 3 & PR04-PR06 & $\begin{array}{l}\text { Category B Training } \\
\text { Prison }\end{array}$ & Attended \\
\hline FG3 & 6 & PR07-PR12 & Category C & Attended \\
\hline FG4 & 2 & PR13-PR14 & Category C & Declined \\
\hline FG5 & 2 & PR15-PR16 & $\begin{array}{l}\text { Category B (Local } \\
\text { Remand) }\end{array}$ & Declined \\
\hline FG6 & 9 & PR17-PR25 & $\begin{array}{l}\text { Category B (Local } \\
\text { Remand) }\end{array}$ & Attended \\
\hline FG7 & 3 & EX1- EX3 & $\begin{array}{l}\text { Community probation } \\
\text { service - Ex-prisoner }\end{array}$ & Mixed \\
\hline FG8 & 6 & ST01-ST06 & $\begin{array}{l}\text { Category B (Local } \\
\text { Remand) }\end{array}$ & \\
\hline FG9 & 2 & ST07-ST08 & Category C & Category C \\
\hline FG10 & 6 & ST09-ST14 & Category C & \\
\hline FG11 & 8 & ST15-ST22 & &
\end{tabular}


Table 2: Barriers and Potential Solutions

\begin{tabular}{|l|r|}
\hline Barrier to attending a health check in prison & Potential Solution \\
\hline $\begin{array}{l}\text { Limited awareness and understanding of the } \\
\text { health check }\end{array}$ & $\begin{array}{l}\text { Posters and adverts shown on wings } \\
\text { and on prison television }\end{array}$ \\
& $\begin{array}{l}\text { 'Health champions' to promote the } \\
\text { health check on prison wings }\end{array}$ \\
\hline Restricted accessibility & $\begin{array}{l}\text { Healthcare staff promoting the health } \\
\text { check to prisoners at other } \\
\text { appointments }\end{array}$ \\
\hline Duplication of other healthcare screens & $\begin{array}{l}\text { Set up temporary clinics on prison } \\
\text { wings }\end{array}$ \\
\hline $\begin{array}{l}\text { Lack of feedback } \\
\text { Two appointments needed if venous blood test } \\
\text { is required }\end{array}$ & $\begin{array}{l}\text { Combine specific healthcare screens } \\
\text { which examine the same risk factors } \\
\text { Incorporate the health check into a } \\
\text { mandatory 'opt-out' second reception } \\
\text { screen }\end{array}$ \\
\hline Lack of motivation & $\begin{array}{l}\text { Provide a results card for prisoners (in } \\
\text { multiple languages) }\end{array}$ \\
\hline
\end{tabular}


Figure 1: Themes from the focus groups

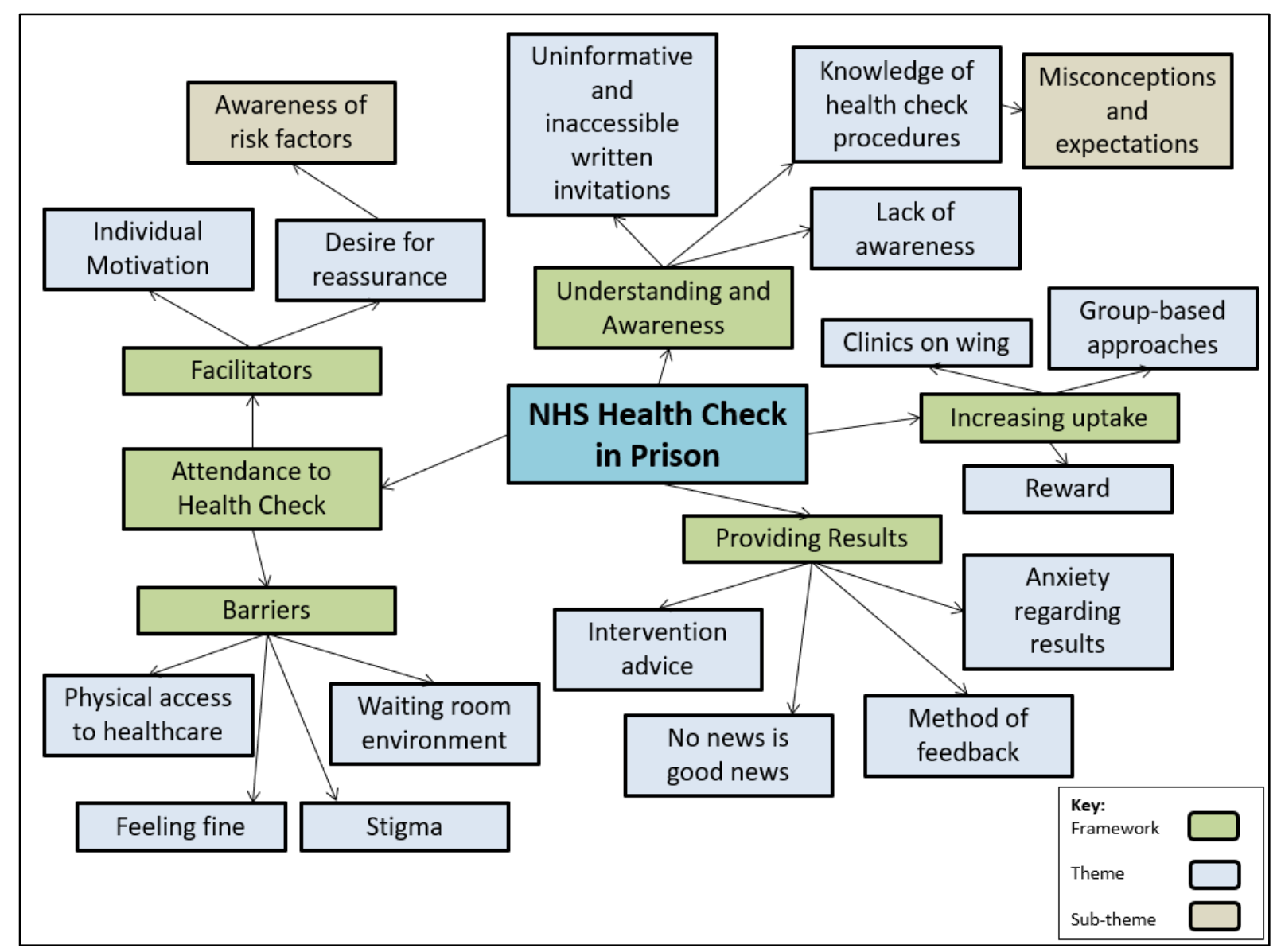




\begin{tabular}{|c|c|}
\hline $\begin{array}{l}\text { Understanding } \\
\text { and Awareness } \\
\text { of Health } \\
\text { Checks }\end{array}$ & $\begin{array}{l}\text { "[It's] all about if you're working right basically innit?" (PRO3, FG1) } \\
\text { "It's like outside, I remember they put these some sort of cables on my chest, like an } \\
\text { ECG or, yeah, then they bring me to hospital and they checked my scan reading, I } \\
\text { think that's a general check-up of getting older like over 40, but in here as we said it } \\
\text { is only taking blood pressure, height, weight, things like that, no machine } \\
\text { whatsoever, that's it" (PR18, FG6) } \\
\text { "you just get a healthcare slip telling you to go to doctor and I don't know what is } \\
\text { happening." (PR18, FG6) }\end{array}$ \\
\hline $\begin{array}{l}\text { Attendance to } \\
\text { Health Checks }\end{array}$ & $\begin{array}{r}\text { Barriers } \\
\text { "... your healthcare appointment that comes through your door, in closed conditions, } \\
\text { but then if they are short staffed or if there is some problem on the wing, that is it } \\
\text { you have missed it as they do not let you out." (EX03, FG7) } \\
\text { "But when you think I'm going up there. I'm going for an appointment for two } \\
\text { minutes then spend all morning there trying to get back you think oh what the hell. } \\
\text { Especially when there's nothing dropping off. You think what's the point." (PRO6, } \\
\text { FG2) } \\
\text { "In all honesty we have enough trouble getting them up to the stuff that they need to } \\
\text { come for, so to get them through the door for something that they don't believe they } \\
\text { need because they are well people, they're not people with hypertension or heart } \\
\text { disease or diabetes, so it's getting them in the door is the hardest part" (ST15, FG11) } \\
\text { "I think with certain people, there is a stigma. Some prisoners would not want to go } \\
\text { healthcare, because for whatever reason if you are assumed to be a bit weak or } \\
\text { whatever, there are some certain prisons where healthcare there has that stigma } \\
\text { attached to it" (EX02, FG7) } \\
\text { "They might be reluctant to do blood tests if they think that's going to be screened } \\
\text { for drugs and there's going to be problems" (PRO6, FG2) } \\
\text { Facilitators } \\
\text { "I do tend to feel that way, you know as I do get older, then I tend to be a bit more } \\
\text { self-aware about what's going on" (EX01, FG7) } \\
\text { "Somebody who's probably just got clean or something... or their lifestyle has been } \\
\text { hectic for a while and they've come in prison, they've got clean, they've got } \\
\text { themselves sorted they want to go and have a health check, check all the different } \\
\text { bloods, see if they've done any lasting damage" (PR15, FG5) }\end{array}$ \\
\hline $\begin{array}{l}\text { Increasing } \\
\text { uptake of the } \\
\text { Health Checks }\end{array}$ & $\begin{array}{l}\text { "Bizarrely I have never understood the resources and logistics of moving people from } \\
\text { one building to another, especially in a local prison - look at the man hours.... Surely } \\
\text { makes more sense for one bloke that needs to see } 50 \text { guys to come to them. ... } \\
\text { Instead of waiting for prisoners to turn up to him, it would just make life easier." } \\
\text { (EX02, FG7) } \\
\text { "ST09: Also it would be nice to have one screening tool because we have that many } \\
\text { screens, diabetic screen, all sorts, elderly } \\
\text { ST10: and a lot of them over-link anyway, so could be doing things twice } \\
\text { tool that can encompass everything, that would be good" (FG10) } \\
\text { ST09: It does seem like we repeat information, so we could have one big screening } \\
\text { "Because you see them when they have the prisoner well-being days they will come } \\
\text { down if they think they're going to get having some fruit or some biscuits or a cup of } \\
\text { tea and that. You know to people on the out, it might seem really quite insignificant } \\
\text { but when you are in prison things that seem quite small are magnified thousands of } \\
\text { times" (STO7, FG9) }\end{array}$ \\
\hline $\begin{array}{l}\text { Providing } \\
\text { Health Check } \\
\text { results }\end{array}$ & $\begin{array}{r}\text { "No news is good news that's what we tell them. If there is something that was found } \\
\text { out then an appointment would be triggered...." (STO4, FG8) } \\
\text { "well how long do you have to wait before you think well I ain't heard nowt yet so I } \\
\text { am guessing it must be ok. You know an exact time, if you are a worrier you could be } \\
\text { sat there panicking like mad." (Unknown, FG6) }\end{array}$ \\
\hline
\end{tabular}


